This item was submitted to Loughborough's Research Repository by the author.

Items in Figshare are protected by copyright, with all rights reserved, unless otherwise indicated.

\title{
Progress towards the design and numerical analysis of a 3D microchannel biochip separator
}

PLEASE CITE THE PUBLISHED VERSION

http://dx.doi.org/10.1002/cnm.1439

PUBLISHER

(C) John Wiley \& Sons Ltd.

VERSION

SMUR (Submitted Manuscript Under Review)

LICENCE

CC BY-NC-ND 4.0

\section{REPOSITORY RECORD}

Xue, Xiangdong, Silvia Marson, Mayur K. Patel, Chris Bailey, William P. O'Neill, David Topham, Robert W. Kay, and Marc P.Y. Desmulliez. 2019. "Progress Towards the Design and Numerical Analysis of a 3D Microchannel Biochip Separator”. figshare. https://hdl.handle.net/2134/13405. 
This item was submitted to Loughborough's Institutional Repository (https://dspace.lboro.ac.uk/) by the author and is made available under the following Creative Commons Licence conditions.

\section{creative
commons}

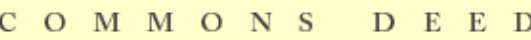

Attribution-NonCommercial-NoDerivs 2.5

You are free:

- to copy, distribute, display, and perform the work

Under the following conditions:

Attribution. You must attribute the work in the manner specified b the author or licensor.

Noncommercial. You may not use this work for commercial purposes.

No Derivative Works. You may not alter, transform, or build upon this work.

- For any reuse or distribution, you must make clear to others the license terms of this work.

- Any of these conditions can be waived if you get permission from the copyright holder.

Your fair use and other rights are in no way affected by the above.

This is a human-readable summary of the Leqal Code (the full license).

\section{Disclaimer 만}

For the full text of this licence, please go to: http://creativecommons.org/licenses/by-nc-nd/2.5/ 


\title{
Progress towards the design and numerical analysis of a 3D microchannel biochip separator
}

\author{
Xiangdong Xue ${ }^{1 \dagger}$, Silvia Marson ${ }^{2}$, Mayur K Patel ${ }^{1}$, Chris Bailey ${ }^{1}$, \\ William O'Neill ${ }^{3}$, David Topham ${ }^{4}$, Robert W. Kay ${ }^{5}$, Marc P.Y. Desmulliez ${ }^{5}$ \\ ${ }^{1}$ CNMPA, School of Computing and Mathematical Sciences, University of Greenwich, London SE10 9LS, UK \\ ${ }^{2}$ Department of Materials, Cranfield University, Cranfield, Bedford MK43 0AL, UK \\ ${ }^{3}$ Institute for Manufacturing, Department of Engineering, University of Cambridge, Cambridge CB2 1RX, UK \\ ${ }^{4}$ School of Engineering and Design, Brunel University, Uxbridge, Middlesex, UB8 3PH, UK \\ ${ }^{5}$ MISEC, School of Engineering \& Physical Sciences, Heriot-Watt University, Edinburgh, EH14 4AS, UK
}

\begin{abstract}
SUMMARY
This paper reports the design and numerical analysis of a three-dimensional biochip plasma blood separator using Computational Fluid Dynamics (CFD) techniques. Based on the initial configuration of a 2D separator, five 3D microchannel biochip designs are categorically developed through axial and plenary symmetrical expansions. These include the geometric variations of three types of the branch side channels (circular, rectangular, disc) and two types of the main channel (solid and concentric). Ignoring the initial transient behaviour and assuming that steady state flow has been established, the behaviour of the blood fluid in the devices is algebraically analysed and numerically modelled. The roles of the relevant microchannel mechanisms, i.e. bifurcation, constriction and bending channel, on promoting the separation process are analysed based on modelling results. The differences among the different 3D implementations are compared and discussed. The advantages of 3D over 2D separator in increasing separation volume and effectively depleting cell-free layer fluid from the whole cross section circumference are addressed and illustrated.
\end{abstract}

KEY WORDS: plasma blood separation; 3D microfluidic device; microchannel device; device design; modelling and simulation

\section{INTRODUCTION}

Traditionally, plasma is separated from blood by centrifugal methods [1]. This approach is however difficult to achieve in microsystem devices where viscous forces usually dominate inertial effects. This challenge has led to an interest in adopting new strategies for the separation of micron size particles [2]. These separation methods can be either classified under mechanical sorting e.g. filters $[3,4]$ or through the use of dynamic forces applied to the cell trajectory. This latter class can be further divided into two categories: i) using external field forces, such as magnetic, electrical, optical, acoustic, thermal and centrifugal, etc. [5,6] and ii) using internal forces $[7,8]$ such as viscous force, shear stress or generated by the device geometric features.

Blood in microchannel systems is generally considered as a suspension of Red Blood Cells (RBCs) in plasma. The RBCs have a biconcave shape with a cytoplasm enclosed by a hyperelastic membrane without a 
nucleus [9]. The diameter of RBCs is approximately $8 \mu \mathrm{m}$ and the thickness of the membrane is $1 \mu \mathrm{m}$ in the centre and $2 \mu \mathrm{m}$ at the edge. RBCs behave like a liquid droplet even at a hematocrit level as high as 98\% [10]. As the size of microchannels becomes comparable to the dimensions of the blood cells, the blood fluid is strongly affected by microchannel characteristics such as constrictions, bifurcations, bending channels, channel geometry and channel surface quality.

A number of researchers have studied the use and behaviour of constrictions [11,12], bifurcations [13,14] and curved sections $[15,16]$ in blood separator devices. A constriction accelerates the flow and increases inertial effects on the fluid. It can also largely increase shear stresses, stretching blood cells within high velocity layers. A bifurcation can be used for separating plasma and blood cell particles, as the particles have a tendency to travel into the channel with the higher flow rate. When the flow rate ratio reaches 8:1 [17], nearly all cells move through the high flow rate channel. A curve in the channel can create a centrifugal force on the fluid, although, in micro devices, a series of multiple curves may be required to enhance this effect [15].

The microfluidic biodevices discussed above have all been built along a two dimensional (2D) architecture in which the microfluidic circuit is manufactured layer by layer and sits on a planar substrate. Existing know-how in traditional design and manufacturing technologies can be referred to or directly put into use for such an approach. With a good understanding of the physics and dynamics of biofluids, the focus of new studies may be shifted to the mechanics of a device for processing within 3D volumetric architecture. $3 \mathrm{D}$ microfluidic devices promise some intrinsic potential benefits compared to more conventional 2D devices: i) space can be used more efficiently resulting in improved space integration, ii) the device functionality can be extended to the whole $3 \mathrm{D}$ space, iii) high-volume manufacturing technologies such as precision machining, milling and injection moulding are appropriate for the manufacture of complex 3D devices, iv) 3D configurations easily adapt to those applications that mimic the natural world, v) the issues associated with clogging can be rendered less critical as the blood has multiple pathways for separation.

A 3D fluidic architecture at the micro-scale behaves differently from its counterpart at the macro-scale. The differences may be categorised as follows:

i) Different channel configurations. In microfluidic systems, channels are integrated into 3D solid systems providing thereby increased structural integrity, strength and stability. A disadvantage is the low quality of the wall surfaces and transition locations such as corners. The choices for the surface material and treatment of the channels are also very limited.

ii) Different geometry characteristics. Due to a high wall surface to volume ratio, microfluidic devices are affected heavily by the channel surface and its characteristics. This is further exemplified by very high length to cross-section ratios. This leads microfluidic channel systems to be relatively large systems and results in a long flow transient regime. Furthermore, when flow achieves a steady state, there is generally no free surface present and shear stress becomes therefore a dominant factor.

The numerical approaches using Computational Fluid Dynamics (CFD) techniques in modelling biomicrofluidic devices generally fall into two categories: i) explicitly modelling of biocells using EulerianLagrangian model for investigating their detailed individual behaviour in local mechanisms by means of the immersed finite element/boundary method (IFEM/IBM) [18,19] or the moving particle semi-implicit method (MPS) [20,21], ii) modelling of the bulk bioflow field in the whole device for predicting the biofluid 
behaviour based on relevant effects or laws [17,22], such as the Fahraeus effect [23] and Fahraeus-Lindqvist [24] effect, the Zweifach-Fung bifurcation law [25], the cell-free layer phenomenon and the bending channel centrifugal effect. The bulk bioflow can be modelled as a single phase liquid, i.e. Eulerian one flow model [26,27], or a multiphase entity, i.e. Eulerian-Eulerian two-flow model [28-30]. This paper adopts the global modelling approach, in which two flows modelled are single phase.

The current research presented in this article is developed from original studies carried out on a 2D Tshaped microchannel separator [31] (Fig. 1). The purpose of this work is to investigate the differences between $2 \mathrm{D}$ and $3 \mathrm{D}$ architectures in the ongoing development of a 3D separator and discern the basic structure of $3 \mathrm{D}$ separators. At this stage only the steady state flow behaviour of the separator has been analysed. It should be noted however that the initial transient filling stage will be important and can affect the overall design, depending on how the device is intended to be used.

\section{DESIGN}

\subsection{Topological development of $3 D$ designs}

Figure 1 depicts the design of a 2D biochip which was the basis for developing the 3D designs detailed in this paper. The biochip consists of a main channel and a series of perpendicularly positioned branch/side channels. The fluid, introduced at the top of the main channel into the separator, passes through a constriction before reaching the bifurcation region where the flow directs the plasma depleted of RBCs through the side channels and an RBC-enriched flow continues through the main channel. The biochip is coupled with the macro part of the system, i.e. Level 2, through its inlet and outlets.

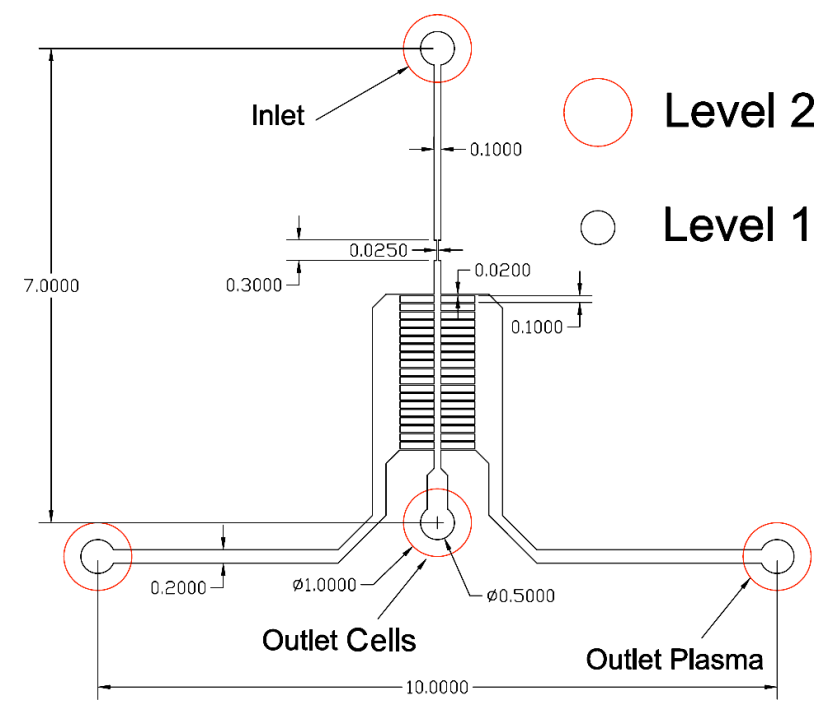

Figure 1. 2D of microfluidic biochip device for plasma blood separation. Dimensions are in millimetres. 
The flow rate ratio between the main and side channels is a key parameter for blood plasma separation. To achieve a high flow rate ratio, the main channel is designed with a larger cross section than the side channels. The outlet of the main channel is also located closer to the bifurcation region than the outlets of the side channels.

The proposed 3D devices are constructed with both axial symmetric and planar symmetric geometries. As axial symmetric systems can provide a uniform condition for flows towards all radial directions, the focus of this paper is put on axial symmetric systems but a design for planar symmetric devices is also discussed.

Figure 2 shows the geometry of 3D Designs I, II and III, which are developed from axial symmetry. All three designs consist of ten layers of $20 \mu \mathrm{m}$ thick side channels. Considering the large number of side channels in each layer, the diameter of the main channel is increased to $150 \mu \mathrm{m}$ from $100 \mu \mathrm{m}$ in the $2 \mathrm{D}$ separator. The constriction is set to $75 \mu \mathrm{m}$ in diameter or a quarter of the area of the main channel. Other geometrical details of the designs are presented in Table I. Geometric parameters of Designs IV and V, the forms of the concentric channel of the device, as well as the 2D separator are also presented in Table I for easy comparison.

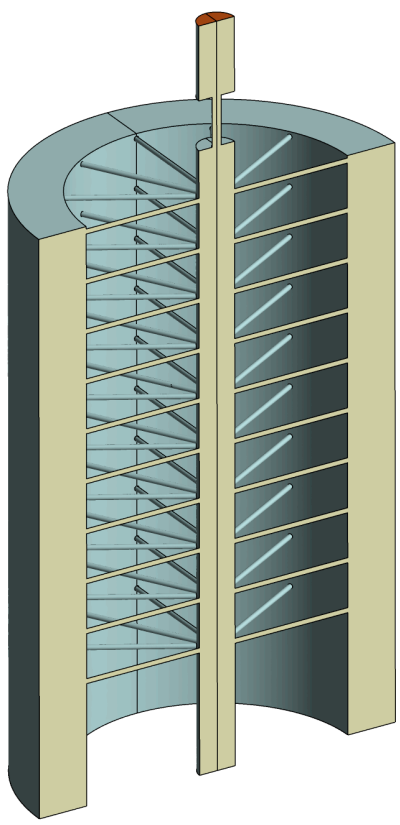

(a)

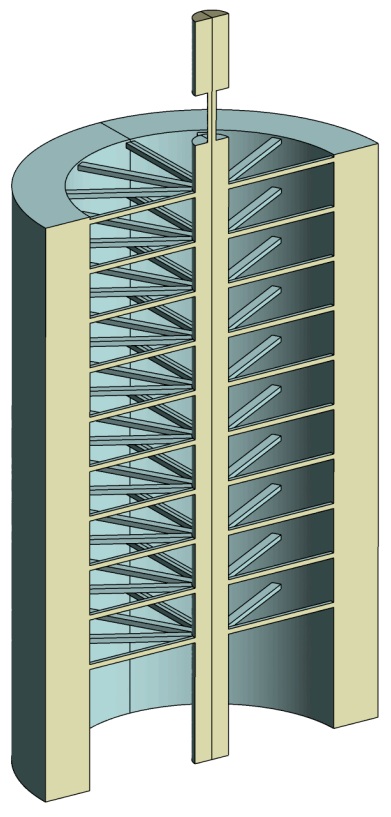

(b)|

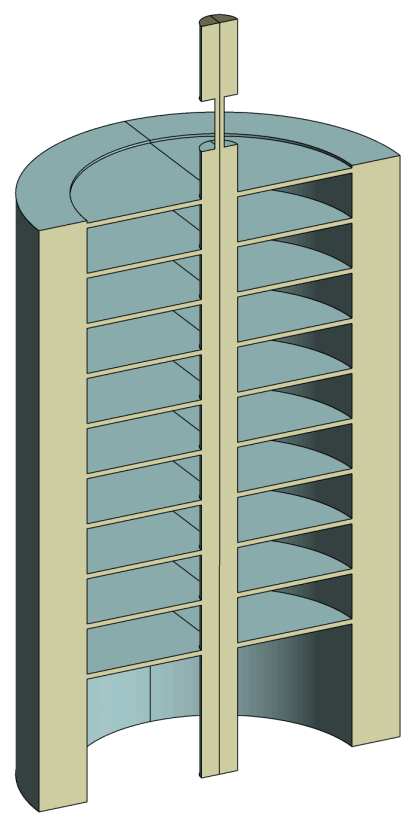

(c)

Figure 2. Topological development of 3D designs, (a) Design I, circular channel; (b) Design II, rectangular channel; (c) Design III, disc channel.

Table I. Shape and size of the 3D designs, length unit: $\mu \mathrm{m}$

\begin{tabular}{clllcl}
\hline \multirow{2}{*}{ Design } & Cross section & Size & Cross section & $\begin{array}{c}\text { Side channel } \\
\text { Channel at } \\
\text { each junction }\end{array}$ & Size \\
\hline 2D & Rectangular & $100 \times 20$ & Square & 2 & $20 \times 20$ \\
I & Circular & $\mathrm{D}=150$ & Circular & 12 & $\mathrm{~d}=20$ \\
II & Circular & $\mathrm{D}=150$ & Rectangular & 12 & $20 \times 20 ;$ \\
& & & & & $20 \times 38$ \\
III & Circular & $\mathrm{D}=150$ & Disc & 1 & $\mathrm{~T}=20$ \\
\hline
\end{tabular}




\begin{tabular}{clllll}
\hline IV & $\begin{array}{l}\text { Concentric } \\
\text { circular }\end{array}$ & $\begin{array}{l}\mathrm{D}=200 ; \\
400\end{array}$ & Rectangular & 12 & $20 \times 102$ \\
V & $\begin{array}{l}\text { Concentric } \\
\text { square }\end{array}$ & $\begin{array}{l}200 \times 200 ; \\
400 \times 400\end{array}$ & Rectangular & 4 & $20 \times 400$ \\
\hline
\end{tabular}

Note: $\mathrm{D}$ and $\mathrm{d}$ refer to the diameters of the main and side channels. $\mathrm{T}$ is the thickness of the disc.

Design I, Design of circular channels, consists of radial branch channels with a pitch of $30^{\circ}$ and each layer consisting of 12 channels. Design II, Design of rectangular channel, is obtained by replacing the circular channels in Design I by rectangular channels. If the number of branch channels is increased indefinitely, the branch channels in each layer will be merged into a disc, resulting in Design III, Design of disc channel.

Depending on the dimensions of the rectangular channels, two variations of Design II result and are referred to as Design IIa or IIb. Design IIa refers to a square branch channel with channel width equal to the diameter of the side channel of Design I. This design is used to compare the flow behaviour between circular and square channels. Design IIb refers to a rectangular branch channel where the channel width is set to a size whose sum equals to the circumference of the main channel. Thus, the difference of Design IIb from Design III is the various straight axial directional channels being used to replace fan shape channels. This is used for a comparison of rectangular and disk channels.

The long extension of the side channel for plasma outgoing region of the 2D separator - whose main functionality was to provide a geometric separation of the side outlets from the main outlet for an easy connection to the macro-world - was not included in the 3D designs.

The above three designs represent the basic building structures of the axial symmetric systems considered. Alternative designs can be developed from changing channel cross-section and/or increasing the number of the main channels. The latter would help the stability of the separation process particularly during the transient filling stage.

\subsection{Designs with concentric main channel}

Fluid separation/skimming at the junctions applies to the fluid close to the wall of the main channel. The flow in the central region of the main channel does not play a part in this process. Accordingly, increased separation efficiency can be achieved by moving the flow in the channel central region to the circumference area. This approach is similar as adopting a concentric main channel. The channel wall interface with the side channels is expended by using a concentric main channel. Consequently, the separation volume is largely increased.

Two designs which include concentric main channels have been analysed. Design IV, Design of concentric circular channel, an extension of Design II, includes a circular concentric main channel, whereas Design V, Design of concentric rectangular channel, includes a rectangular main channel. Designs IV and V are shown in Fig. 3. Both sizes are shown in Table I.

Design $\mathrm{V}$ is a planar symmetrical extension from $2 \mathrm{D}$ to $3 \mathrm{D}$, where the $3 \mathrm{D}$ geometry is developed from the $2 \mathrm{D}$ through extruding the branch channels along two perpendicular directions. This may be viewed as 
four identical planar separators rolled around the main channel. For easy operation, the four out corridors of the branch channels can be connected and merged. In a mathematical model, their behaviours are nearly the same as the current model.

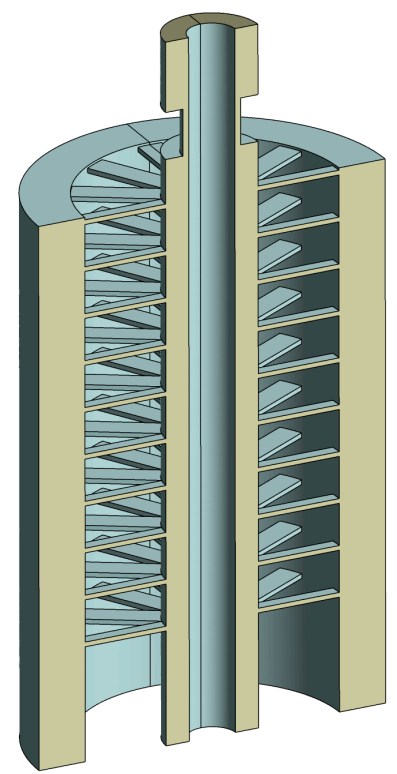

(a)

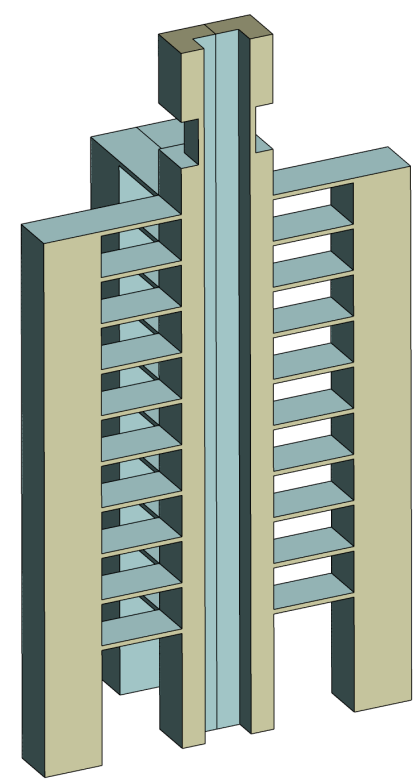

(b)

Figure 3. Designs with concentric main channel, (a) Design VI, circular concentric channel; (b) Design V, rectangular concentric channel.

\subsection{Geometric variations between the designs}

The geometric differences between the five designs lie in the variations of the main and side channels. The design variations for the side channels include circular, rectangular and disc channels. The variations for the main channel include solid and concentric channels.

Table II shows the areas of the cross-sections of the main and side channels for all the designs and the 2D separator. Also presented in the Table II are the total intersection areas between the main and side channels. As the separation process is concentrated in the intersection region, the intersection area gives an instant indication of the separation efficiency.

Table II. Cross-section areas between main and side channels at each junction $\left(\mathrm{mm}^{2}\right)$

\begin{tabular}{lllcc}
\hline Design & $\begin{array}{l}\text { Main } \\
\text { channel }\end{array}$ & $\begin{array}{l}\text { Side } \\
\text { channel }\end{array}$ & $\begin{array}{l}\text { Channel } \\
\text { number }\end{array}$ & $\begin{array}{l}\text { Intersection of } \\
\text { main and side } \\
\text { channels }\end{array}$ \\
\hline 2D & 0.002 & $4 \times 10^{-4}$ & 2 & $8 \times 10^{-4}$ \\
I & 0.01767 & $3.142 \times 10^{-4}$ & 12 & $3.770 \times 10^{-3}$ \\
IIa & 0.01767 & $4 \times 10^{-4}$ & 12 & $4.8 \times 10^{-3}$ \\
\hline
\end{tabular}




\begin{tabular}{lllcl}
\hline IIb & 0.01767 & $7.6 \times 10^{-4}$ & 12 & $9.12 \times 10^{-3}$ \\
III & 0.01767 & $9.425 \times 10^{-3}$ & 1 & $9.425 \times 10^{-3}$ \\
IV & 0.09425 & $2.04 \times 10^{-3}$ & 12 & $2.448 \times 10^{-2}$ \\
V & 0.12 & $8 \times 10^{-3}$ & 4 & $3.2 \times 10^{-2}$ \\
\hline
\end{tabular}

The following geometric differences between designs can be identified from Table II.

i) Square and circular channels. With the same channel sizes, i.e. diameter and/or width of the channels, the total intersection area of a square channel is larger than a circular channel. This is evidenced between the side channels of Designs IIa and I and between the main channels of Designs $\mathrm{V}$ and IV.

ii) Rectangular and disc channels. The total intersection areas are nearly the same, i.e. between Design IIb and III. However, while the upstream ends of the side channels have a similar cross-section, the downstream end of the side channels is very different.

iii) Concentric and solid channels. The total intersection area of the concentric main channel is much larger than the solid centric main channels, as evidenced by Designs IV and IIb.

iv) $2 \mathrm{D}$ and $3 \mathrm{D}$ channels. $3 \mathrm{D}$ separator has a much higher intersection area than the $2 \mathrm{D}$ separator. In $3 \mathrm{D}$ devices, all the circumference of the main channel is coupled with side channels. By contrast, in 2D devices, the main channel can only couple with in plane side channels.

Based on the above differences, it can be initially concluded that i) the concentric channel can result in a higher separation volume than the solid centric channel; ii) the square channel can lead to slightly higher volumetric throughput than the circular channel; iii) the disc channel will behave differently from equal cross section side channels; and iv) a 3D separator designs can give a much higher volumetric separation at each junction than the $2 \mathrm{D}$ separator.

\section{METHOD AND ANALYSIS}

\subsection{Numerical method}

The Navier-Stokes equations for the conservation of mass/continuity and momentum can be expressed as [32]

$$
\begin{aligned}
& \frac{\delta \rho}{\delta t}+\nabla \cdot(\rho v)=0 \\
& \frac{\delta(\rho v)}{\delta t}+\nabla \cdot(\rho v v)=\nabla \cdot \sigma+\rho f
\end{aligned}
$$

where $\boldsymbol{\rho}(x, t)$ and $\boldsymbol{v}(x, t)$ denote the flow density and velocity fields at any position $x$ and time $t, \boldsymbol{\sigma}$ is the stress tensor applied on the enclosing surface and $f$ is the body force applied per unit volume. 
In this study, the flow is treated as incompressible and the slight change of fluid density due to varying hematocrit level across the channel is neglected. Correspondingly $\boldsymbol{\rho}$ is considered as a constant. The flow field is assumed well developed and shows characteristics of a steady flow without change with time. Eqs. (1) and (2) can therefore be simplified as

$$
\begin{aligned}
& \nabla \cdot(v)=0 \\
& \nabla \cdot(v v)=\frac{1}{\rho} \nabla \cdot \sigma+f
\end{aligned}
$$

The Finite Volume (FV) method is used to process the numerical solution of Eqs. (3) and (4). This is a Control Volume (CV) based method, in which the whole domain is firstly discretised into numerical CVs for analysis. The algebraic results are then reassembled to represent the system. The conservation equations of the fluid in a $\mathrm{CV}$ can be obtained by an integral of the physical conservation property in the infinitesimal volume expressed by Eqs. (3) and (4) [33],

$$
\begin{aligned}
& \int_{S} v \cdot n d S=0 \\
& \int_{S} v v \cdot n d S=\int_{S} \frac{1}{\rho} \sigma \cdot n d S+\int_{\Omega} f d \Omega
\end{aligned}
$$

where $\boldsymbol{\Omega}$ and $\boldsymbol{S}$ refer to the volume and the enclosing surface of the $\mathrm{CV}, \boldsymbol{n}$ denotes the unit vector orthogonal to $S$ and directed outwards, $n=\frac{\nabla S}{\|\nabla S\|}$.

The convective terms in the left hand of the equations are numerically solved through interpolation methods. The integrals of the external force and stress tensor in the $\mathrm{CV}$, i.e. the items in the right hand side of Eq. (6), are numerically solved in FV method by the average unit force multiplied by the area or volume of the control volume. That is, $\int_{S} T \cdot n d S=\sum_{k} \int_{S_{k}} T d S$ for pressure and stress and $\int_{\Omega} f \cdot n d \Omega=\bar{f} \Delta \Omega$ for gravitational and centrifugal forces, in which $k$ denotes the surface number of the control volume, $\bar{f}$ and $T=\frac{1}{\rho} \sigma$ the average values in volume $\Omega$ and enclosing surface $\mathrm{S}$.

The boundary conditions in this paper are set as below.

i) Inlet. A specific velocity is applied on the inlet in its normal direction, i.e. $U_{n, \text { inlet }}=C$ and $\frac{\delta U}{\delta n_{i n}}=0$.

ii) Outlet. A static pressure is applied on the outlet boundary, i.e. $p_{\text {stat, outlet }}=p_{0}$.

iii) Channel wall. No-slip wall condition: the velocity of the fluid at the wall boundary is set to zero, i.e. $U_{\text {wall }}=0$.

iv) Symmetry plane. The normal velocity component and the scalar variable gradients normal to the boundary are set to zero, i.e. $U_{n}=0$ and $\frac{\delta \Phi}{\partial n}=0$.

\subsection{Flow field in the designed biochips}




\subsubsection{In main channel}

At the inlet, for the inlet boundary condition of a constant flow velocity, the flow rate at the inlet is determined by the cross section of the main channel at the inlet,

$$
Q=\int_{A_{m}} v \cdot n d A=\int_{A_{m}} v_{\text {axial }} d A
$$

Expressed with average velocity, Eq. (7a) becomes

$$
Q=\bar{v}_{\text {axial }} A_{m}
$$

where $\boldsymbol{v}$ denotes the flow velocity, $v_{\text {axial }}$ and $\bar{v}_{\text {axial }}$ the flow velocity and its average in the axial direction of the channel, $\boldsymbol{Q}$ the flow rate at the inlet, $\mathrm{A}_{\mathrm{m}}$ the cross section of the main channel at the inlet.

Through a constriction the velocity change can be obtained by the mass conservation equation given by Eq. (5). In this paper, the flow velocity in the main channel along the axial direction of the channel is far higher than in the cross-section of the channel. We thus have

$$
\int_{A_{\text {con }}} v_{\text {con }} d A=\int_{A_{\text {cha }}} v_{\text {cha }} d A
$$

where $A$ denotes the channel cross section of the constriction or main channel, $v$ the axial flow velocity in the channel, prefixes con and cha refer to the constriction and main channel, respectively. Using average velocity, Eq. (8a) becomes

$$
\bar{v}_{c o n} S_{c o n}=\bar{v}_{c h a} S_{c h a}
$$

where $\bar{v}_{c o n}$ and $\bar{v}_{c h a}$ denote the average flow velocity in a constriction and the main channel, respectively.

In the junction region of the main channel, the flow velocity varies with the change of flow rate. At junction $i$, the relationship between the flow velocity of the main channel and flow rate can be expressed as

$$
\int_{A_{m}} v_{i} \cdot n d A=\int_{A_{m}} v_{i, \text { axial }} d A=Q_{i}=Q_{0}-\sum_{k=1}^{i} q_{k}
$$

where $\boldsymbol{Q}$ and $\boldsymbol{q}$ denote the flow rates in the main and side channels, respectively. Define $R_{k}=\frac{Q_{k}}{q_{k}}$ as the flow rate ratio at junction $k$, Eq. (9a) becomes

$$
\int_{A_{m}} v_{i, \text { axial }} d A=Q_{0}-\sum_{k=1}^{i} \frac{Q_{k}}{R_{k}}
$$

Expressed by average velocity, we have

$$
\bar{v}_{i, a x i a l} A_{m}=Q_{0}-\sum_{k=1}^{i} \frac{Q_{k}}{R_{k}}
$$

where, $v_{i, a x i a l}$ and $\bar{v}_{i, a x i a l}$ denote the flow velocity and average velocity in the axial direction of the main channel at junction $i, A_{\mathrm{m}}$ the channel cross section of the main channel. Prefix $i, i=0,1,2, \ldots, n$, refers to the junction, in which 0 denotes the inlet end, 1 the most upstream junction and $n$ the last downstream junction. Note that, since $\boldsymbol{Q}_{\mathrm{k}}$ is determined by $\boldsymbol{Q}_{0}$ and $\boldsymbol{R}_{\mathrm{k}}$, the velocity of the main channel is a function of $\boldsymbol{Q}_{0}$ and $\boldsymbol{R}_{\mathrm{k}}$.

Summarising above, we can conclude that:

i) At the inlet, between different designs the flow rate is proportional to the cross section of the main channel, as shown by Eq. (7). 
ii) For a constriction where stable flow has been developed, the average channel velocity is inversely proportional to channel cross-section, as shown by Eq. (8b).

iii) In the junction region, the flow velocity in the main channel decreases with the increase of bifurcation from upstream to downstream, as shown by Eq. (9). The decrease rate is determined by the flow rate ratios at the junctions.

\subsubsection{Side channels}

The flow velocity and flow rate remain the same in the side channels, for the designs with equal crosssection of side channels, i.e. Designs I, II, IV and V. The flow velocity with disc branch channels, i.e. for Design III, however varies along the radial direction. The cross-section of a disc is increased by a rate

$$
\frac{d A_{S}}{d r}=\frac{d}{d r}(2 \pi r H)=2 \pi H
$$

where $\boldsymbol{r}$ denotes the radial distance from the centre of the disc, $\boldsymbol{A}_{\mathbf{s}}$ the circumference cross-section and $\mathrm{H}$ the thickness of the disc. Eq. (10) shows that the cross-section of a disc channel is increased by a constant rate $2 \pi \mathrm{H}$. For an incompressible flow, based on continuity condition, the flow rate in a disc is constant in any circumference, i.e.

$$
\int_{-H / 2}^{H / 2} 2 \pi r \cdot v d h=q
$$

Expressed with average velocity,

$$
2 \pi r H \bar{v}_{\text {radial }}=q
$$

Let $q^{\prime}=\frac{q}{2 \pi H}$, we have

$$
\bar{v}_{\text {radial }}=\frac{q^{\prime}}{r}
$$

or

$$
\bar{v}_{\text {radial }} r=q^{\prime}=\mathrm{constant}
$$

where $\bar{v}_{\text {radial }}$ denotes the average flow velocity in the radial direction, $\boldsymbol{q}$ the constant flow rate in the disc. The rate of change of velocity can be then expressed as

$$
\frac{\delta \bar{v}}{\delta r}=\frac{d \bar{v}_{\text {radial }}}{d r}=\frac{d}{d r}\left(\frac{q^{\prime}}{r}\right)=-\frac{q^{\prime}}{r^{2}}
$$

Besides flow rate/velocity, the development of flow field is also affected by the volume of the channel. The ratio of the channel volumes between disc channel, i.e. Design III, and rectangular channel, i.e. Design $\mathrm{IIb}$, can be expressed as

$$
\lambda_{v o l}=\frac{\pi\left(r_{2}^{2}-r_{1}^{2}\right) H}{2 \pi r_{1}\left(r_{2}-r_{1}\right) H}=\frac{1}{2}\left(\frac{r_{2}}{r_{1}}+1\right)
$$

where $r_{2}$ and $r_{1}$ denote the disc radius at circumference and the radius of the main channel. For this design, $\lambda_{v o l}=2.5$. With the same size of the main channel and input flow rate, the separated flow rate from the 
side channels of Design III is similar to that of Design IIb. The development period of flow field in Design III is thus much slower than Design IIb. We can therefore conclude for the design of the disc channel, that:

i) The velocity is a function of the radial distance and is hyperbolically distributed along radial direction of the disc, as shown by Eq. (12).

ii) The flow velocity decreases with a rate of square radius of the disc when the fluid flows from the centre to the edge of the disc, as shown by Eq. (13).

iii) Comparing with the designs with equal cross-section of side channels, the design with disc channel requires more time to develop the flow field and to achieve a converging solution.

\section{MODELLING}

\subsection{CFD Model}

Two flow models have been used too represent the separation feature. The fluid in the side channels and subsequent the outflow region is modelled as a plasma of constant viscosity of $0.0015 \mathrm{~Pa} \cdot \mathrm{s}$ and constant density of $1025 \mathrm{~kg} / \mathrm{m}^{3}$. The flow in the main channel is modelled as a non-Newtonian bulk blood fluid.

The Carreau-Yasuda model, shown below, is used for modelling the shear-thinning non-Newtonian behaviour of the fluid [34]:

$$
\mu(\dot{\gamma})=\mu_{\infty}+\frac{\mu_{0}-\mu_{\infty}}{\left(1+(\lambda \dot{\gamma})^{b}\right)^{a}}
$$

where $\dot{\gamma}$ is the shear rate, $\mu_{\infty}$ and $\mu_{0}$ are the infinite shear viscosity and the zero shear viscosity, respectively; $\lambda$, $\mathrm{a}$ and $\mathrm{b}$ are constants. Parameter values are as follows [35]: $\mu_{\infty}=0.0035$ Pa.s, $\mu_{0}=0.16$ Pa.s, $\lambda=8.2 \mathrm{~s}, \mathrm{a}=$ 1.23 and $b=0.64$. The fluid density is taken as $\rho=1060 \mathrm{~kg} / \mathrm{m}^{3}$.

Symmetric computational models are used to simplify the simulation process. Based on the symmetric nature of the device, the half models shown in Figs. 2 and 3 are further simplified. A quarter of the geometry is modelled for Designs I, II, IV, V and a $30^{\circ}$ section of geometry for Design III. Figure 4 shows the computational models for Designs II and V. The numbers of nodes and elements of all the models are detailed in Table III.

For the boundary conditions, the inlet is set to a constant velocity of $50 \mathrm{~mm} / \mathrm{s}$ along its normal direction. This corresponds to a constant flow rate of $3.18 \mathrm{ml} / \mathrm{h}$ for Designs I, II and III, $16.9 \mathrm{ml} / \mathrm{h}$ for Design IV and $21.6 \mathrm{ml} / \mathrm{h}$ for Design $\mathrm{V}$. The boundary conditions at the main and side outlets are set to $0 \mathrm{~Pa}$ pressure. 


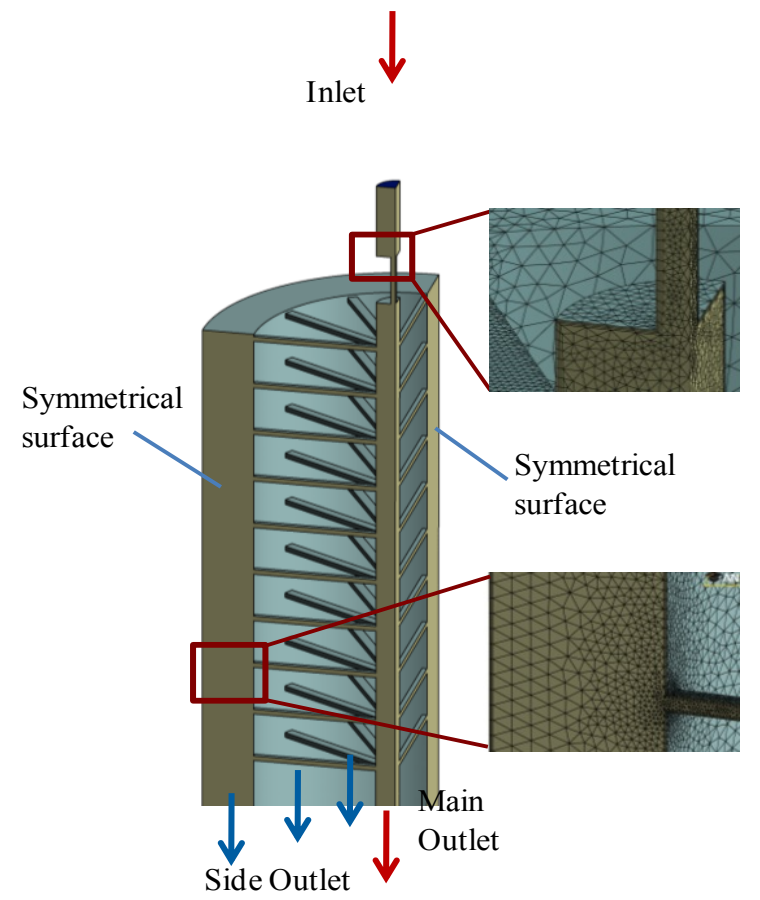

(a)

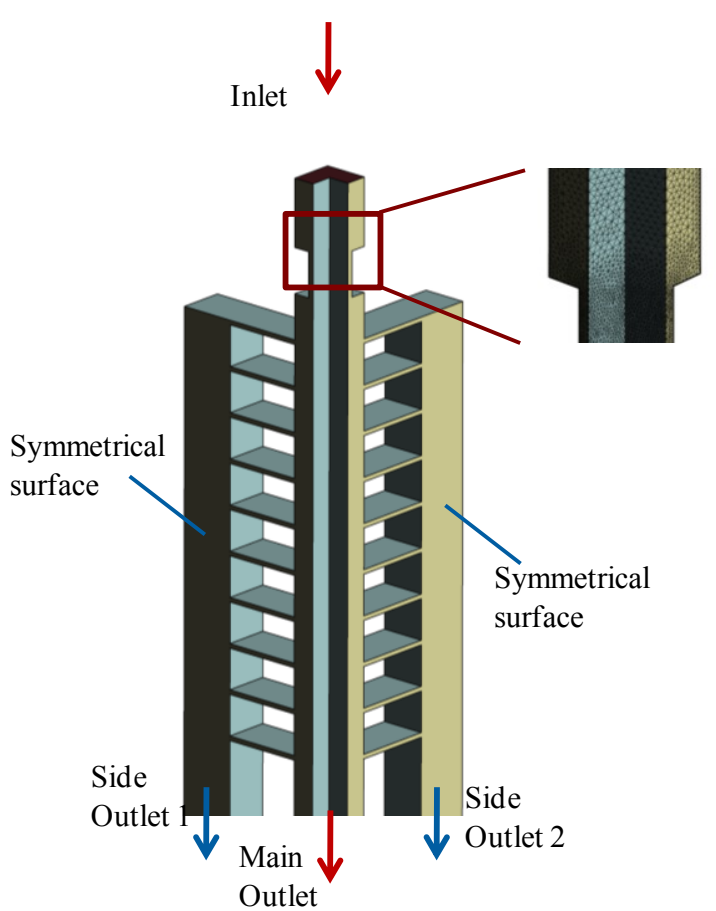

(b)

Figure 4. Computational models of Designs (a) IIb and (b) Design V

Table III. Numbers of nodes and elements contained in designs

\begin{tabular}{lccccc}
\hline Design & I & II & III(b) & IV & V \\
\hline Node & 886053 & 1179606 & 1429084 & 7036301 & 2117091 \\
Element & 3396624 & 4541598 & 5673705 & 1700454 & 8303705 \\
\hline
\end{tabular}

The accuracy and stability of the numerical process is affected by three aspects: i) Mathematical modelling error, i.e. how different the governing Navier-Stokes equations and relevant assumptions are from the reality; ii) Numerical modelling error, i.e. how different the numerical discretization and boundary conditions in FV method are from the governing equations; iii) Solution process error, i.e. how accurate the iterations and convergence are in solving the numerical model. The considerations for these three aspects are as follows.

i) Assumptions in mathematical modelling. The assumptions of steady and incompressible flows have been well-accepted for microfluids with low Reynolds numbers. The effect of the channel size on viscosity and heamatocrit, which is related to Fahraeus effect [23] and Fahraeus-Lindqvist effect [24], has little effect on the discussed models. As two flows, bulk blood and plasma, are modelled for the flow in the main and side channels respectively, the channels where sizes change appear only in the plasma region.

ii) Discretization in numerical modelling. In FV method, the information of a discretised CV is concentrated at a single central grid and the entail region in the $\mathrm{CV}$ adopts a constant value. As a result, the larger the $\mathrm{CV}$ size and the gradient of the flow field, the higher the discretization error. In order to reduce discretization error and also keep the model in a reasonable size, different densities of elements are assigned in different regions based on the gradient of the flow field. Accordingly the 
intersection region between the main and side channels and the constriction are assigned to meshes finer than the outgoing region of the plasma and the central region of the main channel. To take into account the sharp change of the flow field close to the wall, three thin layers are set in wall boundary layer. See Fig. 4 for details.

iii) Solution setup. (a) Interpolation scheme: The high resolution scheme in CFX5, a second order scheme, is adopted for solving the equations. (b) Timestep: Auto timestep which is internally calculated based on boundary conditions, flow conditions, physics and geometry, is used. This yields a timestep of $4.7 \times 10^{-3} \mathrm{~s}$ for Designs I, IIa and IIb and $3.4 \times 10^{-3} \mathrm{~s}$ for Design III. (c) Convergence criteria: $10^{-6}$ root mean square (RMS) as a normalised residual, referring to a tight convergence, is used for convergence criteria. (d) Boundary conditions: Constant flow rates on the Inlet and static pressure of $0 \mathrm{~Pa}$ at outlets, a robust boundary condition, are adopted. As the flow field in the biochip is only determined theoretically by the relative pressure between the inlet and outlets, the result is also applicable to realistic pressure levels which are non-zero as the biochip is coped within the macro part.

iv) Convergence history. Figures 5 and 6 respectively show the convergence histories of U momentum (axial direction of the side channel) and $\mathrm{V}$ momentum (axial direction of the main channel) for Designs I to III. For an effective comparison, these were given the same settings for mesh densities and distribution. For a clear view, some data in earlier iterations have not been included in the figures. Comparably, U momentum converged faster than $\mathrm{V}$ momentum. The designs with equal cross section channels, i.e. Designs I, IIa and IIb, converged faster and more stable than the design with disc channel, i.e. Design III. Part reason of this is due to the different channel volume of Design III from others, as shown in Eq.(14).

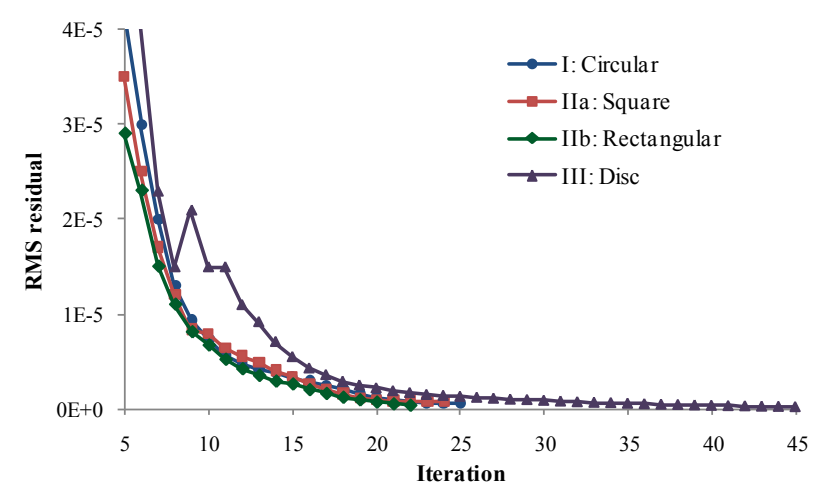

Figure 5. Convergence history of RMS residual of U-momentum equation 


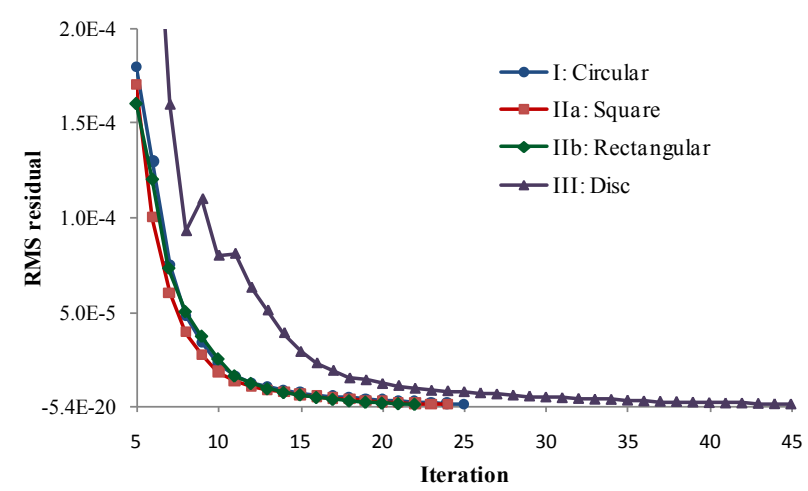

Figure 6. Convergence history of RMS residual of V-momentum equation

\subsection{Common features among the designs}

Designs I, II and III are modelled as three basic designs. The three designs are built with a same main channel and varying shaped side channels. The flow field in the main channel is analysed firstly to investigate the general common features of the designs. The flow fields in the side channels are then analysed to examine the differences between designs.

The flow separation efficiency is mainly determined by the flow rate ratio between the main and side channels. Based on Zweifach-Fung bifurcation law [25], when the flow rate ratio reaches 8:1 and above, nearly all plasma can be separated from the blood via the daughter channel with low flow rates [17].

Figure 7 shows the profiles of the flow rate ratios for Designs I, II and III over different junctions. All flow rate ratios in the three designs are higher than 8:1, indicating a potential successful separation. As the main channel is the same between different designs the flow rate ratio decreases with an increase of side channel cross sections. From a flow rate ratio point of view, Designs III and IIb have a similar separation behaviour among different junctions, which is more balanced than Designs I and IIa.

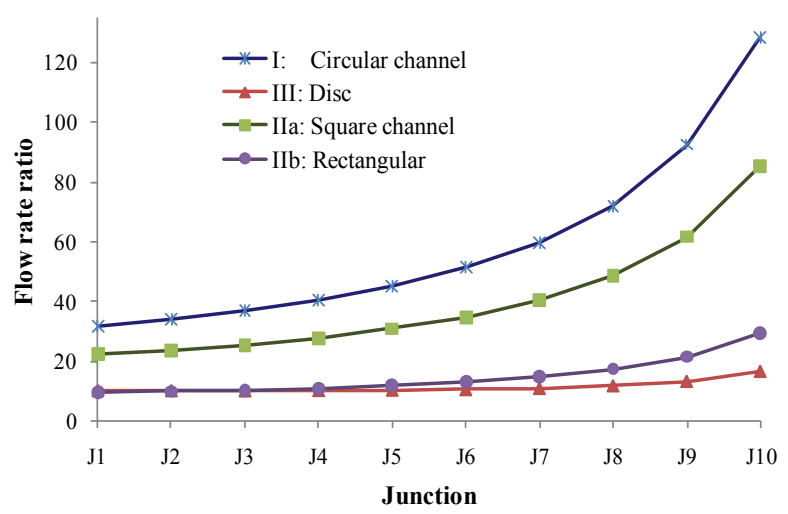

Figure 7. Flow rate ratio profiles of Designs I (Circular), IIa (Square), IIb (Rectangular) and III (Disc)

Figure 8 shows the Reynolds number at the inlet and outlet ends of the main channel for Design IIb. The Reynolds numbers at the other junctions of this design falls within the region between the two curves. Between Designs I, IIa, IIb and III, the Reynolds numbers are the same at the inlet end and show only slight differences at the outlet end. The low Reynolds number confirms that the flow is laminar in behaviour. The cell-free layer is thus kept in the slow moving fluid within the laminar layers close to main channel wall. 
RBC behaviour is closely related to Reynolds number and the viscosity of the bulk fluid $[31,36]$. When the Reynolds number is higher than 1 but still in the laminar regime, RBCs flip around themselves, a behaviour generally referred to as tumbling motion. This is the case for the current designs. As the Reynolds number becomes less than $1, \mathrm{RBCs}$ are difficult to move as a whole due to the restriction from increased viscous effect in the blood flow. Relative shear motions between the membrane and the centre of the cell are then induced, appearing either as a tank-treading or swinging motion $[39,40]$.

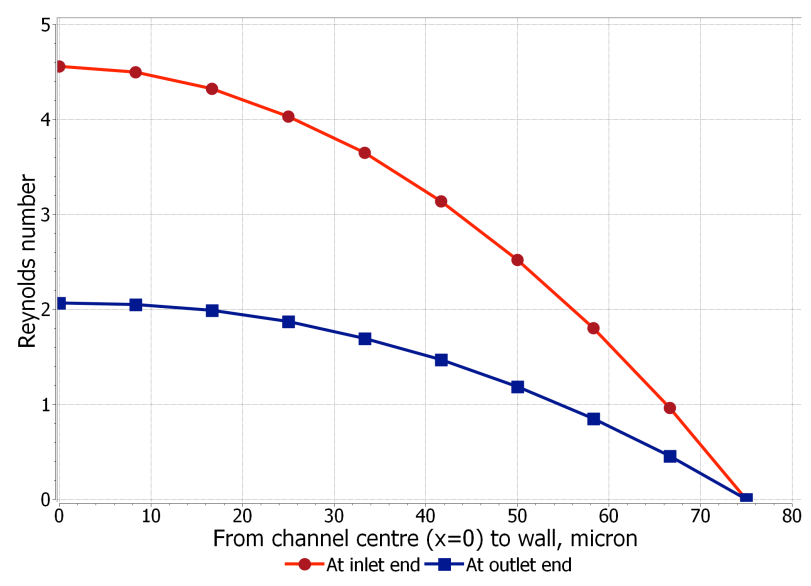

Figure 8. Reynolds number in main channel, Design IIb

Figure 9 shows the flow velocity profiles of Designs I, II and III when passing through the constriction and within the main channel. The velocity of the flow displays a parabolic behaviour. The ratio between the constriction and main channel peak velocities is around 4. This is equal to the difference of the cross section areas in agreement with Eq. (8b). Under parabolic distribution, the gradient of the velocity and shear rate close to the wall is much higher than at the central region of the main channel. In the region close to the wall, cells are more susceptible to be deformed and can exhibit cross layer motion.

The constriction may also induce a difference in velocities between RBCs and plasma. Based on Fahraeus effect [23], the flow hematocrit in the constriction is lower than the main channel. It was observed [39] that, in a diameter of $20 \mu \mathrm{m}$ channel, the flow viscosity is about half of the normal value. As the thickness of the cell-free layer is relatively constant [11,40], to keep the same hematocrit between the main channel sections coupled with the two ends of the constriction, RBCs have to move faster than the plasma. The induced velocity difference can increase the hydrodynamic effect between RBCs and plasma.

Due to the higher velocities through the constriction and thus higher shear gradient, the hyperelastic membrane of the blood cells is likely to be stretched along the streamlines. The cells are likely therefore to be located in the layers close to the channel centre. This helps enhance the separation process which takes place in the region close to the main channel wall. 


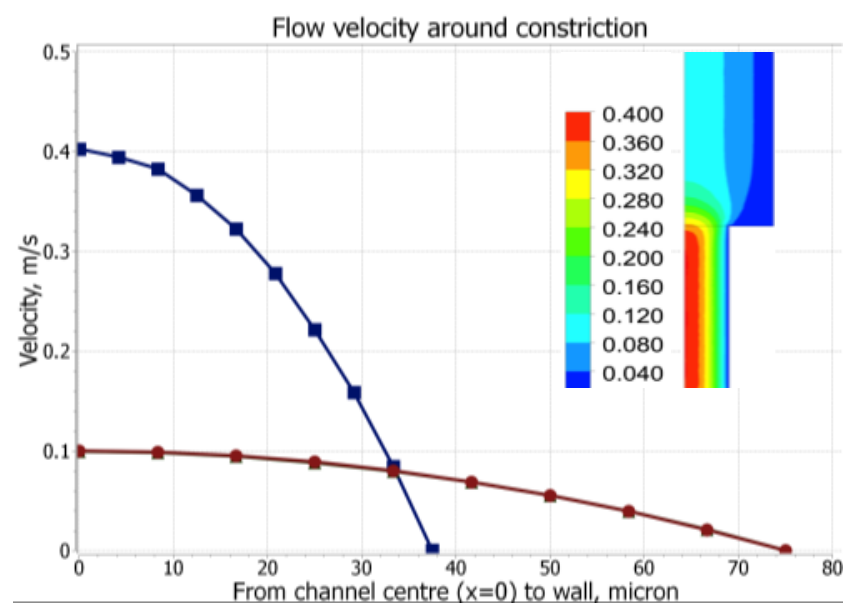

Figure 9. Flow velocity around the constriction with velocity contour inserted

Figure 10 shows the flow velocity vectors at the second junction of Design IIa. Other junctions and other designs show a similar pattern. The laminar flow feature can be clearly seen. Only the fluid close to the main channel wall where the cell-free layer is located is skimmed into the side channel. For a particle located at the stagnant point, the velocity at the main channel side is higher than the side channel side. Higher friction force and lower pressure will thus be formed in the main channel side, inducing the movement of the particle towards the main channel. Taking the side channel $(20 \mu \mathrm{m}$ in width) as a reference for size, the thickness of flow layers which enter the side channel from the main channel ranges between 9-10 $\mu \mathrm{m}$. As this is thicker than the $8 \mu \mathrm{m}$ cell-free layer in microchannels [39], some other separation effects could also come into play. These could include:

i) Bending channel effect. As the flow enters the side channel, it experiences a curved trajectory. Under centrifugal force the blood cell which has a higher mass density than the surrounding plasma has a tendency to escape the bending flow and returns to the main channel.

ii) Magnus effect [41] and Saffman effect [42]. The shear stresses across the RBC cell in the direction of the cross-channel direction are different due to the parabolic profile of the flow velocities. This may cause the particle to spin. The whirl field produced by the spin in turn increases the velocity difference. A pressure gradient is thus formed and a transverse force pointing to the side of higher flow velocity, i.e. the channel centre, is induced.

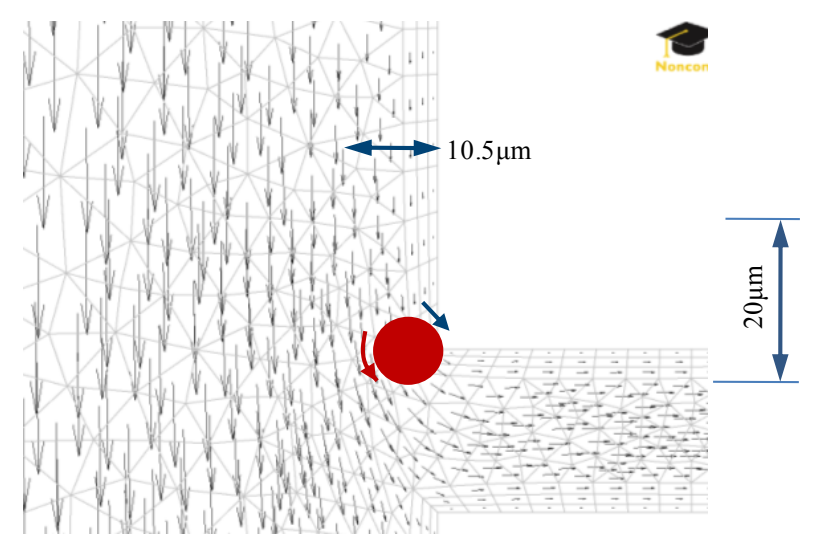

Figure 10. Velocity vector at the second junction of Design IIa 


\subsection{Differences between the designs}

\subsection{1. $3 \mathrm{D}$ versus $2 \mathrm{D}$ systems}

There are two clear differences between $2 \mathrm{D}$ and $3 \mathrm{D}$ designs as far as the separation process is concerned. One is the difference in volumetric separation which has been indicated in Table II by the difference of the cross section interface between the 3D designs and the 2D separator. Figure 11 shows the modelling result of the ratio of the flow rates between the side channels of 3D Design IIb and 2D separator. The difference in separated volumetric flow rate between 3D and 2D separators is about one order of magnitude. 3D separator thus has far higher volumetric separation efficiency than the 2D device.

The other difference between 2D and 3D designs refers to the efficiency in draining the cell-free layer flow. Figure 12 shows the simulation result of the velocity profiles at a 2D bifurcation and a 3D junction, respectively. While the 3D design can separate the fluid from the cell-free layer in all the circumference of the main channel, the 2D separator can only deplete the fluid from the cell-free layer in the two in-plane sides. Featured with laminar flow, the cell-free layer fluid close to the in-plane wall in the 2D separator becomes difficult to collect. Comparing with its $2 \mathrm{D}$ counterpart, 3D separator thus has an advantage in depleting cell-free layer flow from the whole circumference of the channel.

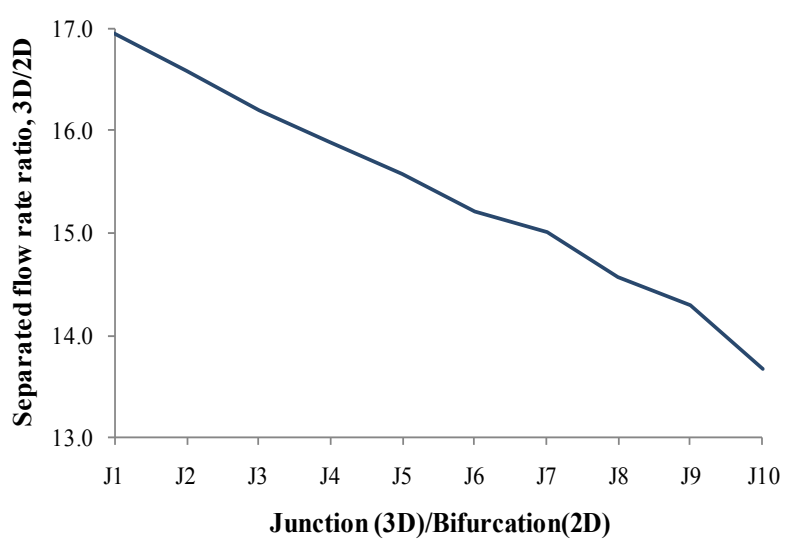

Figure 11. Flow rate proportion between the 3D and 2D side channels

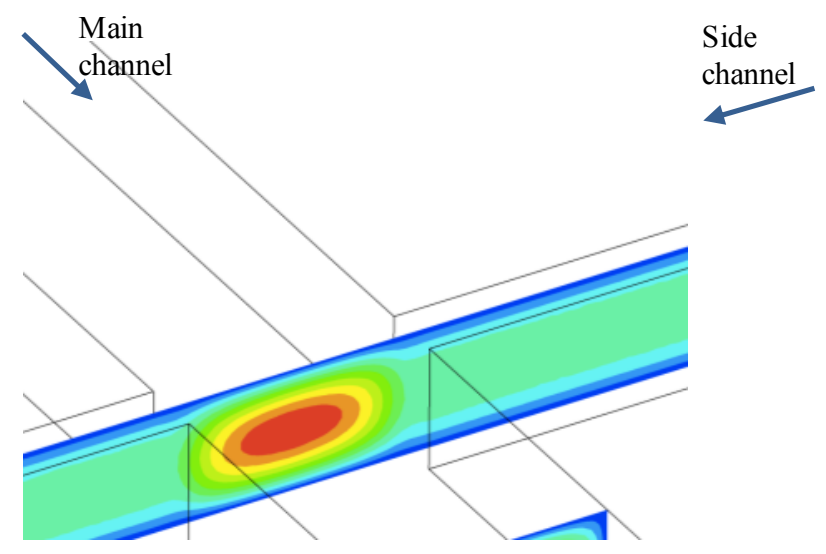

(a) $2 \mathrm{D}$ channel 


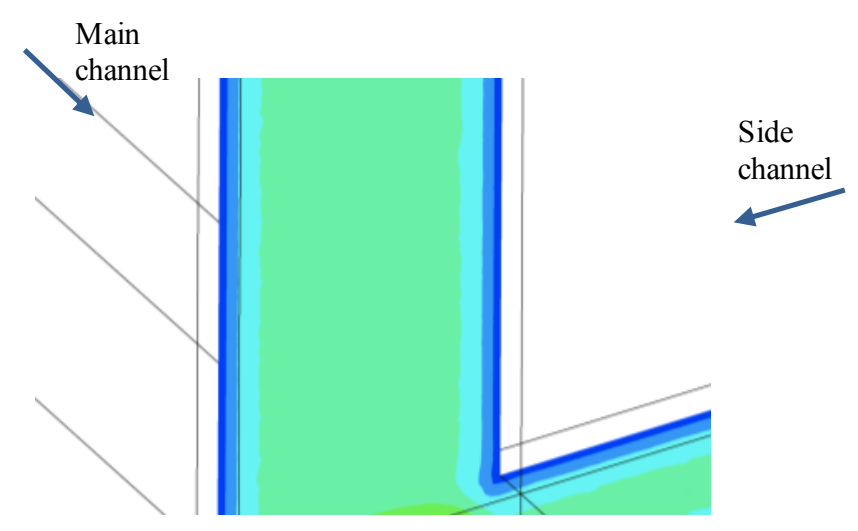

(b) 3D channel

Figure 12. Velocity profiles at (a) 2D bifurcation and (b) 3D junction (warm colours represent high velocity)

\subsubsection{Disc versus rectangular channels}

The disc channel differs from equal cross-sectional channel by its varying cross-section in the axial direction. The fluid experiences a fan section and thus an increased channel cross section when moving from the centre of the disc to the edge. Based on the continuity condition given by Eqs. (5) and (11), the flow velocity changes along the axial direction of the disc. Figure 13 shows the modelling results for the peak velocity profile in the radial direction for Design III. The profile of curves shows hyperbolic distribution, as expected by Eq. (12).

The other geometrical feature of a disc is that it possesses a single side channel to deliver the fluid to all directions. As there is no vertical wall along any axial direction, the channel resistance is low, resulting in increased volumetric separation. However, without restriction in the lateral direction, the flow can easily be deflected laterally. Hence, from the point of flow field stability, equal cross section channel like Design IIb has an advantage over the disc channel. This is evidenced by the convergence histories shown in Figs. 5 and 6.

Design IIb by rectangular channel is compared with Design III, as they have the same intersection between the main and side channels. Figure 14 shows the modelling results for the flow rate separated by the side channels from different junctions of Designs IIb and III. The disc channel design gives more volumetric separation, due to less channel resistance. The rectangular channel shows a near straight line, indicating a more stable performance than the disc channel.

Figure 15 shows the pressure profiles for Designs III and IIb at the ends of the side channels. Due to its higher channel resistance, the rectangular channel in Design IIb requires higher pressure than the disc channel in Design III. 


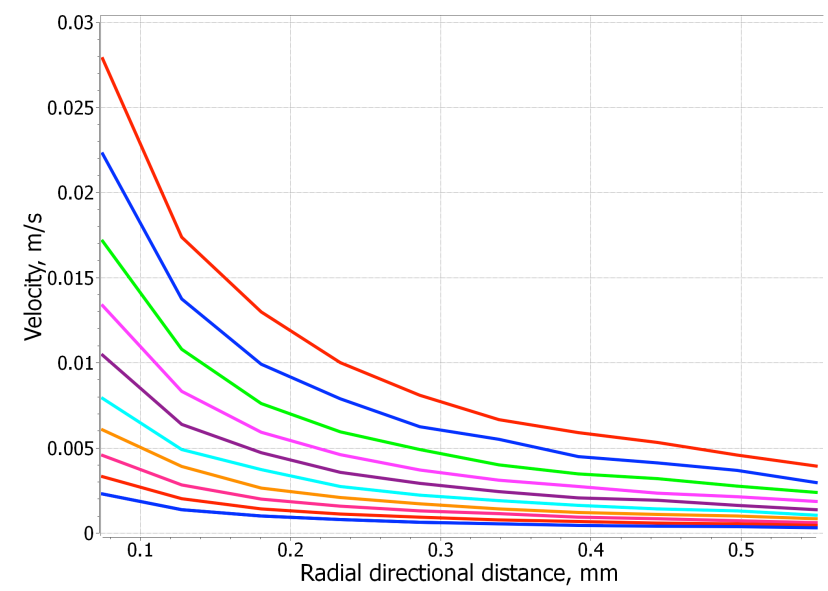

Figure 13. Velocity profile of Design III along disc radial direction (upstream channels located in the top region)

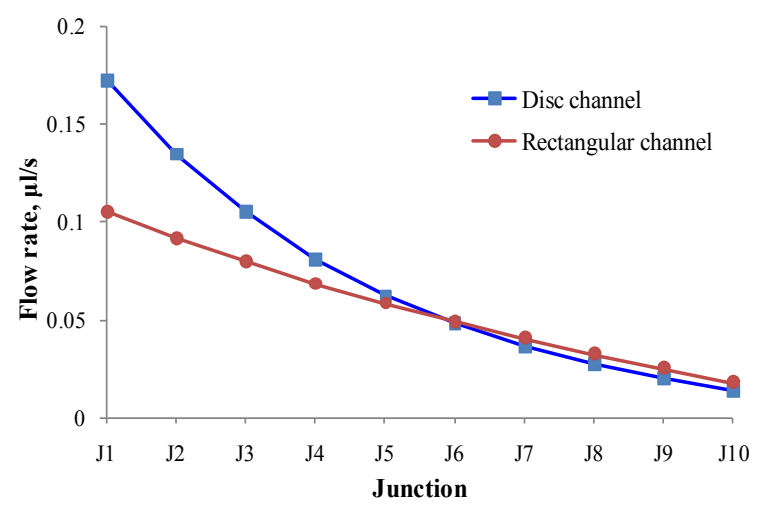

Figure 14. Flow rate of side channels of disc channel (Design III) and rectangular channel (Design IIb)

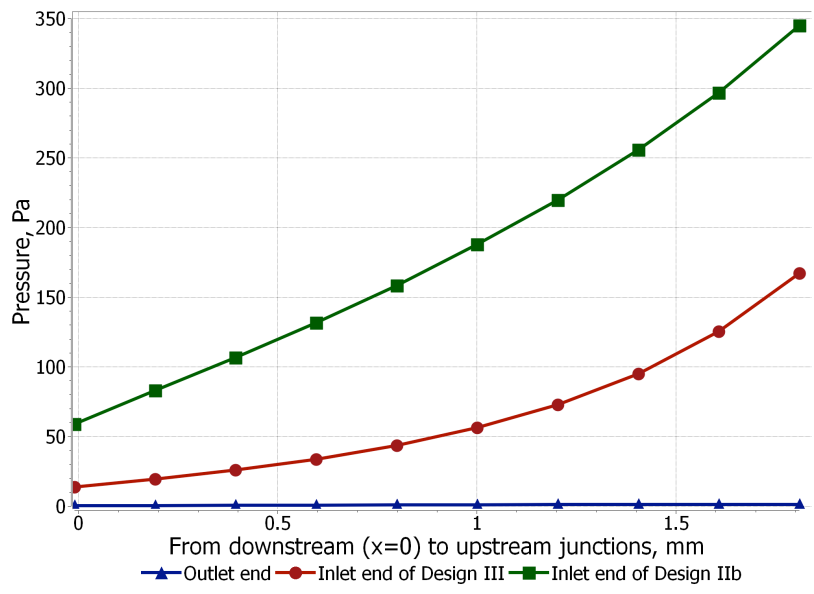

Figure 15: Pressure drop on side channels for Designs IIb (rectangular) and III (disc)

\subsubsection{Solid versus concentric channels}

Geometrically the difference between a concentric channel and a solid channel lies in the much larger intersection area between the main and side channels for the concentric configuration as indicated in Table II. Concentric main channels can thus increase the separation volume. 
Figures 16 and 17 show the profiles of the flow rate ratio and flow rate, respectively, of concentric designs IV, $\mathrm{V}$ and solid rectangular design IIb over different junctions. A common geometrical feature of these three designs is that the rectangular side channels are mounted in all circumferences of the main channels. The trends of the curves of the flow rate ratio are similar among the three designs, indicating a similar separation pattern over the junctions. The development of flow rate separated by the side channels is however very different between two concentric channels and the solid channel. The concentric designs have separated a much higher flow through the side channels than the solid design. We can thus conclude that concentric designs have a similar separation pattern as the solid designs but can lead to a much higher volumetric separation of the fluid.

Note that Designs IV and V belong to the axial and planar symmetric systems, respectively. Based on Figs 16 and 17, these two symmetric systems behave similarly in both separation pattern and separation volume.

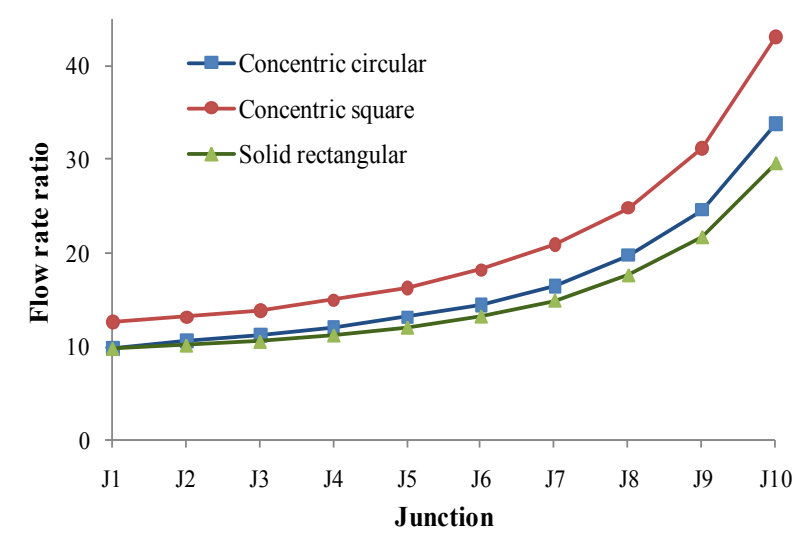

Figure 16. Flow rate ratio of Designs IV, V and IIb across different junctions

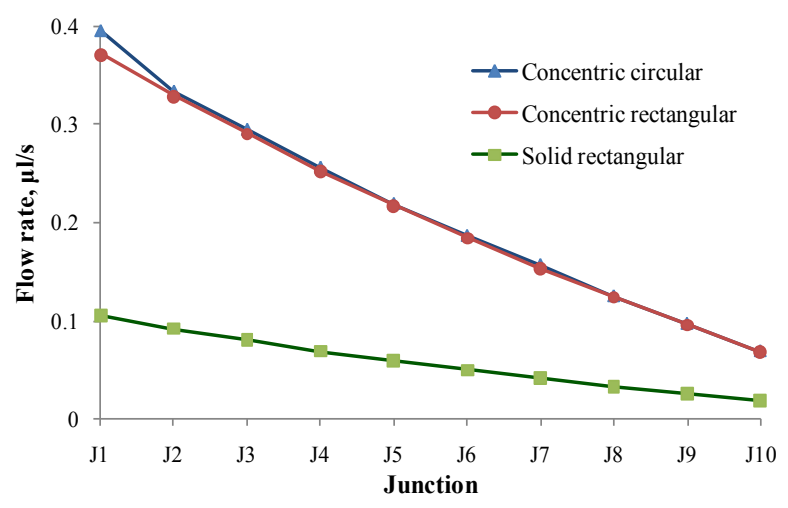

Figure 17. Flow rate separated by side channels, of Designs IV, V and IIb

\subsubsection{Circular versus square channels}

The comparison refers to Designs I vs. IIa and Design IV vs. V, respectively. The diameter of the circular side channel of Design I is equal to the edge length of the square side channel of Design IIa. The diameters of the concentric circular channel of Design IV are also equal to the edge lengths of the concentric square channels of Design V. Designs I and IIa and Designs IV and V are thus comparable.

Table VI shows the area rate of cross sections between Designs I and IIa and between Designs IV and V. With the same character size, for both solid and concentric channels the cross section area of a square 
$\mathrm{d} \stackrel{\overline{\mathrm{D}}}{\mathrm{in}} \overline{\overline{0}} \underset{\mathrm{in}}{200 \mu \mathrm{m}}$

channel is 1.27 times that of a circular channel. This indicates that a square channel can separate more volumetric fluid than a circular channel, as illustrated by Eq. (8).

Table VI. Difference of square and circular channels with same dimensions

\begin{tabular}{|c|c|c|}
\hline Cross section & $\begin{array}{l}\text { Side channel } \\
\text { Designs I (circular) } \\
\text { Design IIa (square) }\end{array}$ & $\begin{array}{c}\text { Main concentric channel } \\
\text { Design IV (circular) } \\
\text { Design V (square) }\end{array}$ \\
\hline \multicolumn{3}{|l|}{ Geometry } \\
\hline \multirow[t]{2}{*}{ Area } & $A_{\text {circular }}=\frac{\pi}{4} d^{2}$ & $A_{\text {circular }}=\frac{\pi}{4}\left(D_{\text {out }}^{2}-D_{\text {in }}^{2}\right)$ \\
\hline & $A_{\text {square }}=d^{2}$ & $A_{\text {square }}=\left(D_{\text {out }}^{2}-D_{\text {in }}^{2}\right)$ \\
\hline Area ratio & $\frac{A_{\text {square }}}{A_{\text {circle }}}=\frac{4}{\pi}=1.27$ & $\frac{A_{\text {square }}}{A_{\text {circle }}}=\frac{4}{\pi}=1.27$ \\
\hline
\end{tabular}

Figures 18 and 19 show the flow rate of the total side channels and the flow rate ratio of Designs I and IIa. The square side channel of Design IIa has separated more flow than the circular side channel of Design I. The increased volumetric separation by the side channels of Design IIa leads to a decrease of its flow rate ratio.

The comparison of concentric and solid channels for Designs IV and V with regards to the main channel is different from the previous discussion. The input flow rate of the concentric square Design $\mathrm{V}$ should be $27 \%$ larger than the concentric circular design IV, as shown in Table V later. The flow rate and flow rate ratio of Designs IV and V have been shown in Figs. 16 and 17. For the volumetric separation through the side channels (Fig. 17), the flow rate curves of Designs IV and V are very similar indicating the same volumetric separation between Design IV and V. As the input flow rate in the main channel of Design V is higher than Design IV, Design V has a higher flow rate ratio than Design IV (Fig. 16). We can thus conclude that, when used for side channels, a circular and a square channels can lead to $27 \%$ difference in volumetric separation, whereas when used for main channels, circular and square channels do not result in significantly different volumetric separation. 


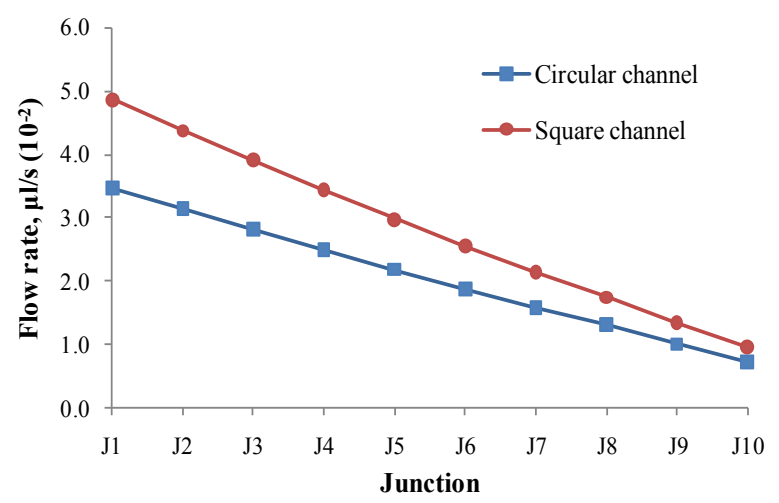

Figure 18. Flow rate of side channels of Designs I and IIa

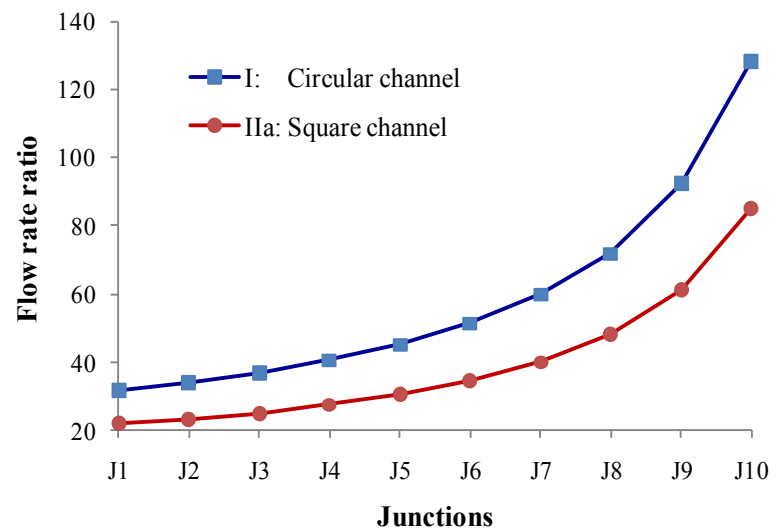

Figure 19. Flow rate ratio of Designs I and IIa

\subsubsection{Flow rate and flow rate ratio of the devices}

Table V summaries the flow rate at the inlet and outlet boundaries of different designs. The increase in flow rate by the concentric designs from the solid designs is equal to the increase of the cross section of the main channel as shown in Table 2 and Eq. (7).

Table VI shows the flow rate ratio at different junctions of the designs. The flow rate ratio here is calculated by taking into account the sum of the flow rates of all the side channels. All flow rate ratios are higher than the threshold 8:1, indicating numerically that all the designs can lead to a successful separation of plasma from the main channel. Their distribution is however unbalanced among different junctions, implying the need for optimization for improved performance.

Table V. Flow rate for designs at inlet and outlet (unit: $\mu \mathrm{l} / \mathrm{s}$ )

\begin{tabular}{cccccccc}
\hline Design & 2D & I & IIa & IIb & III & IV & V \\
\hline Inlet & 0.01 & 0.882 & 0.882 & 0.882 & 0.883 & 4.71 & 6.0 \\
Main outlet & 0.00595 & 0.709 & 0.653 & 0.406 & 0.0867 & 2.59 & 3.44 \\
Side outlet & 0.00405 & 0.176 & 0.230 & 0.478 & 0.800 & 2.11 & 2.56 \\
\hline
\end{tabular}

Table VI. Flow rate ratio of designs through all side channels

\begin{tabular}{llllllll}
\hline Design & 2D & I & IIa & IIb & III & IV & V \\
\hline
\end{tabular}




\begin{tabular}{llllllll}
\hline Jun 1 & 14.5 & 31.7 & 21.5 & 9.73 & 10.2 & 9.78 & 12.6 \\
Jun 2 & 15.3 & 34.0 & 22.9 & 10.1 & 10.2 & 10.7 & 13.2 \\
Jun 3 & 16.0 & 36.9 & 24.6 & 10.5 & 10.1 & 11.2 & 13.9 \\
Jun 4 & 17.2 & 40.5 & 26.9 & 11.2 & 10.2 & 12.0 & 15.0 \\
Jun 5 & 18.7 & 45.2 & 29.9 & 12.0 & 10.4 & 13.1 & 16.3 \\
Jun 6 & 20.6 & 51.4 & 33.7 & 13.2 & 10.5 & 14.5 & 18.2 \\
Jun 7 & 23.5 & 59.9 & 39.1 & 14.9 & 10.9 & 16.4 & 20.9 \\
Jun 8 & 27.6 & 71.9 & 47.4 & 17.6 & 11.8 & 19.8 & 24.8 \\
Jun 9 & 33.8 & 92.7 & 60.1 & 21.7 & 13.2 & 24.7 & 31.2 \\
Jun 10 & 44.6 & 128 & 83.1 & 29.6 & 16.5 & 33.9 & 43.2 \\
\hline
\end{tabular}

\section{CONCLUSIONS}

Five variants of 3D biochip separators have been developed by way of axial and planar symmetric expansions. The designs adopt circular, rectangular and disc channels for the side branch channels and solid and concentric channels for the main channel. From the results presented above the following can be concluded:

1) Numerically all designs can successfully separate plasma from bulk flow. Overall, all designs with the side channels of equal cross sections show an increasing trend of flow rate ratio from upstream to downstream junctions as illustrated by the 2D separator [43]. The design with disc side channels shows a different pattern due to varying cross section of the side channels in the radial direction.

2) The channel characteristics of constriction, bifurcation and channel geometry show strong effects on the blood flow field and play an important role in promoting plasma blood separation.

3) Comparing with the $2 \mathrm{D}$ separation device, the cross section of the main channel and the coupled intersection between the main and side channels are largely increased in 3D separator, leading to a much higher throughput and separated flow rates than the 2D separator. Different from the in-plane separation mode by the $2 \mathrm{D}$ separator, 3D separator can deplete plasma in the cell-free layer from the whole circumference of the channel cross section, bringing in an increase of the separation efficiency.

4) Comparing the separation efficiency between solid and concentric main channels, the separation volume of the concentric channel is largely increased with increase in intersection area. Comparing the separation between circular and square cross sections of the side channels, a square channel can separate slightly more flow rate than a circular channel.

5) In terms of separation volume, the design using a disc channel has a lower resistance than the design of circular and rectangular channels and results in more volume separated. In terms of flow field stability and convergent speed, as the cross section of Disc Channel is gradually changed when flow going to the circumference of the disc from the centre, flow velocity field is nonlinearly changed and converges slower than the designs with equal cross section channels.

The five proposed designs offer flexible choice depending of the field of application. In terms of separation performance, the square channels device can produce more volumetric separation than the circular 
channel, and the channels with equal cross sections have an advantage for flow field stability over disc channel. Therefore, Design II and its concentric channel version Design V are recommended when high throughput and high flow stability are required.

In the current study the focus is on the conceptual designs and patterns of the 3D separators. Future work will address the fabrication of the proposed devices to validate the paper results. In particular i) a further modification of the 3D biochip based on the application requirements in manufacturing; ii) a study of a new design with multiple feed channels for increased volumetric separation of the device.

\section{ACKNOWLEDGEMENTS}

This work is funded by the UK Engineering and Physical Sciences Research Council (EPSRC) through the Grand Challenge Project '3D-MINTEGRATION', referenced EP/C534212/1. The authors would also like to acknowledge the contribution from Ms. Maiwenn Kersaudy-Kerhoas concerning the 2D separator design.

\section{REFERENCES}

1. Hester JP, Kellogg RM, Mulzet AP, Kruger VR, McCredie KB and Freireich EJ. Principles of blood separation and component extraction in a disposable continuous-flow single-stage channel. Blood 1979; 54: 254-68.

2. Kersaudy-Kerhoas M, Dhariwal RS, Desmulliez MPY. Recent advances in microparticle continuous separation. IET Journal of Nanobiotechnology 2008; 2: 1-13.

3. Carlson R, Gabel C, Chan S, Austin R. Self-sorting of white blood cells in a lattice. Phys. Rev. Lett. 1997; 79: 2149-2152.

4. Heng CK, Lim TM, Yobas L, Ji HM, Samper V, Chen Y. Silicon-based microfilters for whole blood cell separation. Biomed Microdevices 2008; 10: 251-257.

5. Ramadan Q, Samper V, Poenar D., Yu C. Magnetic-based microfluidic platform for biomolecular separation. Biomed Microdevices 2006; 8: 151-158.

6. Rhee SW, Taylor AM, Cribbs DH, Cotman CW, Jeon NL. External force-assisted cell positioning inside microfludic devices. Biomed Microdevices 2007; 9: 15-23.

7. Mohamed H, Turner JN, Caggana M. Biochip for separating fetal cells from maternal circulation. Journal of Chromatography A 2007; 1162: 187-192.

8. Aoki R, Yamada M, Yasuda M, Seki M. In-channel focusing of flowing microparticles utilizing hydrodynamic filtration. Microfluid Nanofluid 2009; 6: 571-576.

9. Korin N, Bransky A, Dinnar U. Theoretical model and experimental study of red blood cell (RBC) deformation in microchannels. Journal of Biomechanics 2007; 40: 2088-2095.

10. Fung YC. Biomechanics - mechanical properties of living tissues. Springer: New York, 1993.

11. Faivre M, Abkarian M, Bickraj K, Stone H. A Geometrical focusing of cells in a microfluidic device: A route to separate blood plasma, BioRheology 2006; 43: 147-159.

12. Layek GC, Midya C. Effect of constriction height on flow separation in a two-dimensional channel. Commun Nonlinear Sci Numer Simul 2007; 12: 745-759. 
13. El-Kareh AW, Secom TW. A model for red blood cell motion in bifurcating microvessels. International Journal of Multiphase Flow 2000; 26: 1545-1564.

14. Jaggi RD, Sandoz R, Effenhauser CS. Microfluidic depletion of red blood cells from whole blood in high-aspect-ratio microchannels. Microfluid Nanofluid 2007; 3: 47-53.

15. Di Carlo DD, Edd JF, Irlmla D, Tompkins RG, Toner M. Equilibrium separation and filtration of particles using differential inertial focusing. Anal. Chem. 2008; 80: 2204-2211.

16. Sollier E, Rostainga H, Pouteaua P, Fouillet Y, Achard JL. Passive microfluidic devices for plasma extraction from whole human blood. Sensors and Actuators B: Chemical 2009; 141: 617-624.

17. Yang S, Undar A, Zahn JD. A microfluidic device for continuous, real time blood plasma separation. Lab Chip 2006; 6: 871-880.

18. Peskin CS. Numerical analysis of blood flow in the heart. Journal of Computational Physics 1977; 25: 220-252.

19. Liu WK, Liu Y, Farrell D, Zhang L, Wang XS, Fukui Y, Patankar N, Zhang Y, Bajaj C, Lee J, Hong J, Chen X, Hsu H. Immersed finite element method and its applications to biological systems. Comput. Methods Appl. Mech. Engrg. 2006; 195: 1722-1749.

20. Koshizuka S, Nobe A, Oka Y. Numerical analysis of breaking wave using the moving particle semiimplicit method. International Journal for Numerical Methods in Fluids 1998; 26: 751-768

21. Kamada H, Tsubota K, Nakamura M, Wada S, Ishikawa T, Yamaguchi T. A three-dimensional particle simulation of the formation and collapse of a primary thrombus. International Journal for Numerical Methods in Biomedical Engineering 2010; 26: 488-500.

22. Chein R, Tsai SH. Microfluidic flow switching design using volume of fluid model. Biomed Microdevices 2004; 6: 81-90.

23. Fahraeus R. The suspension stability of the blood. Physiol. Rev. 1929; 9: 241-274.

24. Fahraeus R., Lindqvist T. The viscosity of the blood in narrow capillary tubes. Am. J. Physiol. 1931; 96: $562-568$.

25. Fung YC. Stochastic flow in capillary blood vessels. Microvasc. Res. 1973; 5: 34-48.

26. Qiu Y, Tarbell JM. Numerical simulation of pulsatile flow in a compliant curved tube model of a coronary artery. Journal of Biomechanical Engineering 2000; 122: 77-85.

27. Steinman DA. Image-based computational fluid dynamics modeling in realistic arterial geometries. Annuals of Biomedical Engineering 2002; 30: 483-497.

28. Anderson TB, Jackson R. A fluid mechanical description of fluidized beds. J \& EC Fundamentals 1967; 6: $524-539$.

29. Shapiro E, Drikakis D, Gargiuli J, Vadgama P. Interface capturing in dual-flow microfluidics. Journal of Computational and Theoretical Nanoscience 2007; 4: 802-806.

30. Shapiro E, Drikakis D. Non-conservative and conservative formulations of characteristics numerical reconstructions for incompressible flows. International Journal for Numerical Methods in Engineering 2006; 9: 1466-1482.

31. Kersaudy-Kerhoas M, Dhariwal R, Desmulliez MPY, Jouvet L. Hydrodynamic blood plasma separation in microfluidic channels. Microfluid Nanofluid 2010; 8: 105-114. 
32. Prosperetti A, Tryggvason G. Computational Methods for Multiphase Flow. Cambridge University Press: Cambridge, 2007.

33. Ferziger JH, Peric M. Computational Methods for Fluid Dynamics, 2nd rev. ed. Springer: London, 1999.

34. Gijsen FJH, van de Vosse FN, Janssen JD. The influence of the non-Newtonian properties of blood on the flow in large arteries: Steady flow in a carotid bifurcation model. J. Biomech. 1999; 32: 601-608.

35. Leuprecht A, Perktold K. Computer simulation of non-Newtonian effects on blood flow in large arteries. Comput. Methods Biomech. Biomed. Eng. 2001; 4: 149-163.

36. Abkarian M, Viallat A. Vesicles and red blood cells in shear flow. Soft Matter 2008; 4: 653-657.

37. Abkarian M, Faivre M, Viallat A. Swinging of red blood cells under shear flow. Phys Rev Lett 2007; 98(18): 188302.

38. Zhang J, Johnson PC, Popel AS. Effects of erythrocyte deformability and aggregation on the cell free layer and apparent viscosity of microscopic blood flows. Microvascular Research 2009; 77: 265-272.

39. Woodcock JP. Physical properties of blood and their influence on blood-flow measurement. Rep. Prog. Phys. 1976; 39: 65-127.

40. Fujiwara H, Ishikawa T, Lima R, Matsuki N, Imai Y, Kaji H, Nishizawa M, Yamaguchi T. Red blood cell motions in high-hematocrit blood flowing through a stenosed microchannel. Journal of Biomechanics 2009; 42: 838-843.

41. Dandy DS, Dwyer HA. A sphere in shear flow at finite Reynolds number: effect of shear on particle lift, drag, and heat transfer. J Fluid Mech 1990; 216: 381-410.

42. Saffman PG. The lift on a small sphere in a slow shear flow. J Fluid Mech 1965; 22: 385-400.

43. Xue X, Patel MK, Kersaudy-Kerhoas M, Bailey C, Desmulliez MPY. Modelling and simulation of the behaviour of a biofluid in a microchannel biochip separator. Comput. Methods Biomech. Biomed. Eng. In press-Accepted manuscript, DOI: 10.1080/10255842.2010.485570. 